\title{
Pemberdayaan Perempuan Mace Mace Papua Untuk Meningkatkan Kesejahteraan Keluarga Daerah Tujuan Wisata Pantai Kampung Malaumkarta Distrik Makbon Kabupaten Sorong
}

\author{
Nanik Purwanti ${ }^{1 *}$, Uswatul Mardliyah $^{2}$, Masniar $^{3}$, Ana Lestari $^{4}$, Saiful Ichwan $^{5}$ \\ 1, 2, 3, 4, 5 Universitas Muhammadiyah Sorong, Indonesia \\ Email: *purwantinanikums@gmail.com
}

\begin{abstract}
ABSTRAK
Pemberdayaan Perempuan Mace Mace Papua di Kampung Malaumkarta melalui partisipasi perempuan dalam pemenuhan kebutuhan ekonomi rumah tangga adalah gambaran upaya mengangkat derajat kehidupan masyarakat dari belenggu kemiskinan. Kegiatan PKM ini menggunakan metode penyuluhan kepada masyarakat, dengan melakukan observasi,wawancara dan dokumentasi. Partisipasi perempuan Mace Mace Papua kampung Malaumkarta di daerah tujuan wisata pantai saat ini tidak sekedar menuntut persamaan hak tetapi menyatakan bahwa mereka mampu membantu dalam memenuhi kebutuhan keluarga dan dapat berkiprah disektor publik sembari menjalankan tugas-tugas domestiknya dalam rumahtangga.
\end{abstract}

Kata kunci: Pemberdayaan Perempuan;Mace Mace Papua;Kesejahteraan Keluarga

\section{Empowering Mace Mace Papuan Women to Improve Family Welfare in Malaumkarta Village Beach Tourism Destinations Makbon District, Sorong Regency On January 16, 2021}

\begin{abstract}
The empowerment of Mace Papuan women in Malaumkarta Village through the participation of women in meeting household economic needs is an illustration of an effort to raise the level of people's lives from being tied to poverty. This PKM activity uses outreach methods to the community, by conducting observations, interviews and documentation. The participation of Mace Mace Papuan women in the Malaumkarta village in coastal tourism areas is currently not only demanding equal rights but also stating that they are able to meet family needs and can take part in the public sector to carry out their domestic tasks in the household.
\end{abstract}

Keywords: Women Empowerment; Mace Mace Papua; Family Welfare

\section{PENDAHULUAN}

Perempuan, bagimanapun juga tetap merupakan kekuatan utama perubahan. Penyesuaian kebijakan, baik sebagai perwujudan kesetaraan wanita dan pria, maupun untuk memampukan wanita mengaktualisasikan potensinya, dapat memberikan dampak yang berarti pada ekonomi. Hal ini berarti harus dijamin agar kebijakan jangka pendek dan sedang tidak memberi dampak negatif pada wanita, dan konsisten dengan tujuan jangka panjang untuk mencapai kesetaraan. Selanjutnya perlu memandang transformasi stuktural jangka panjang sebagai wahana untuk mengakomodasikan peran ekonomi wanita yang semakin meningkat bagi peningkatan kesejahteraan masyarakat pada umumnya (Ihromi,Tapi Omas,2006).

Pemberdayaan perempuan tidak hanya merupakan proses kolektif, politik atau sosial, tetapi juga harus berlangsung pada tingkat indiviual. Pemberdayaan perempuan tidak hanya merupakan suatu proses, tetapi juga merupakan hasil bahwa: perempuan menjadi manusia yang mempunyai kemampuan mengontrol dan memberi arah pada kehidupannya sendiri. Orang lain tidak bisa memberdayakan perempuan. Perempuan sendiri yang harus dapat melakukannya sendiri dengan cara mampu membuat pilihan, mampu menyuarakan pendapatnya, kebutuhannya sebagai perempuan. Akan tetapi, institusi-institusi yang ada di tingkat nasional dan kerjasama 
internasional dapat membantu proses pengembangan kepercayaan diri perempuan, peningkatan harga diri perempuan dan membantu perempuan menyusun agenda kegiatannya bagi diri sendiri (Ihromi,Tapi Omas,2006).

Kegiatan Pengabdian Kepada Masyarakat ini dilaksanakan di kampung Malaumkarta Distrik Makbon, karena ketertarikan Kami terhadap daerah ini sebagai daerah tujuan wisata pantai di Kabupaten Sorong, sebagai salah satu alternative tempat rekreasi masyarakat Kabupaten Sorong dan Kota Sorong. Daerah tujuan wisata pantai kampung Malaumkarta tidak hanya banyak diminati masyarakat lokal tetapi juga dari manca negara. Kami berharap dengan penyuluhan ini,Mace Mace Papua kampung Malaumkarta dapat memanfaatkannya dengan mengembangkan potensi dirinya diluar ranah domestik untuk mendapatkan penghasilan tambahan sehingga dapat meningkatkan kesejahteraan keluarga.

\section{Tujuan}

1. Tujuan Umum

Meningkatkan cara berpikir,bersikap dan bertindak Mace Mace Papua Kampung Malaumkarta sehingga dapat memanfaatkan Daerah Tujuan Wisata Pantai untuk meningkatkan kesejahteraan keluarga.

2. Tujuan Khusus

a. Menemukan, merumuskan, serta memecahkan berbagai masalah yang berkaitan dengan Mace Mace Papua Kampung Malaumkarta sehingga Kami dapat membantu memberikan jalan keluar dari permasalahan tersebut.

b. Menambah wawasan Dosen terutama dibidang pemberdayaan perempuan.

c. Memperkenalkan Perguruan Tinggi kepada masyarakat.

d. Membantu masyarakat maupun pemeintah setempat untuk menggali potensi yang dimiliki oleh Maca Mace Papua Kampung Malumkarta.

\section{METODE}

Kegiatan Pengabdian Kepada Masyarakat ini dilaksanakan di kampung Malaumkarta Distrik Makbon, dengan mengunakan beberapa metode, yaitu:

1. Penyuluhan yaitu dengan Pemaparan materi tentang pengertian pemberdayaan perempuan secara umum.

2. Wawancara secara terbuka kepada Mace Mace Papua untuk mengetahui permasalahan atau kesulitan yang dihadapi dan membantu memecahkan permasalahan tersebut,sehingga dapat memberi manfaat bagi mereka.

\section{HASIL DAN PEMBAHASAN}

Kegiatan Pengabdian Kepada Masyarakat merupakan salah satu perwujudan dari Tri Dharma Perguruan Tinggi yaitu Pengabdian Kepada Masyarakat. Pengabdian ini merupakan suatu wujud pelaksanaan pengamalan ilmu pengetahuan, teknologi dan seni budaya langsung pada masyarakat secara kelembagaan melalui metodologi ilmiah untuk mengembangkan kemampuan masyarakat, sehingga dapat mempercepat laju pertumbuhan tercapainya tujuan pembangunan nasional.

Kegiatan Pengabdian Kepada Masyarakat bagi dosen diharapkan dapat menjadi suatu pengalaman belajar yang baru untuk menambah pengetahuan, kemampuan dan kesadaran hidup bermasyarakat (Laporan KKN). Bagi masyarakat, kegiatan ini diharapkan mampu memberikan motivasi dan kreativitas dalam mengembangkan potensi diri Mace Mace Papua kampung Malaumkarta untuk meningkatkan kesejahteraan keluarga.

Sebagai salah satu wujud dari Tri Dharma Perguruan Tinggi, Kami melaksanakan Pengabdian Kepada Masyarakat di kampung Malaumkarta Distrik Makbon Kabupaten Sorong, dalam kegiatan penyuluhan mengambil tema tentang Pemberdayaan Perempuan. Materi penyuluhan dengan judul PEMBERDAYAAN PEREMPUAN MACE MACE PAPUA .UNTUK MENINGKATKAN KESEJAHTERAAN KELARGA DAERAH TUJUAN WISATA 
PANTAI.

Kami diterima baik oleh Bapak Kepala Kampung dan masyarakat. Kegiatan PKM mendapat tanggapan secara positif. Kami melakukan kegiatan Pengabdian kepada Masyarakat di Kampung Malaumkarta yang bertujuan untuk membangun, mengembangkan dan memberikan motivasi kepada masyarakat khususnya Mace Mace Papua untuk berkehidupan lebih maju.
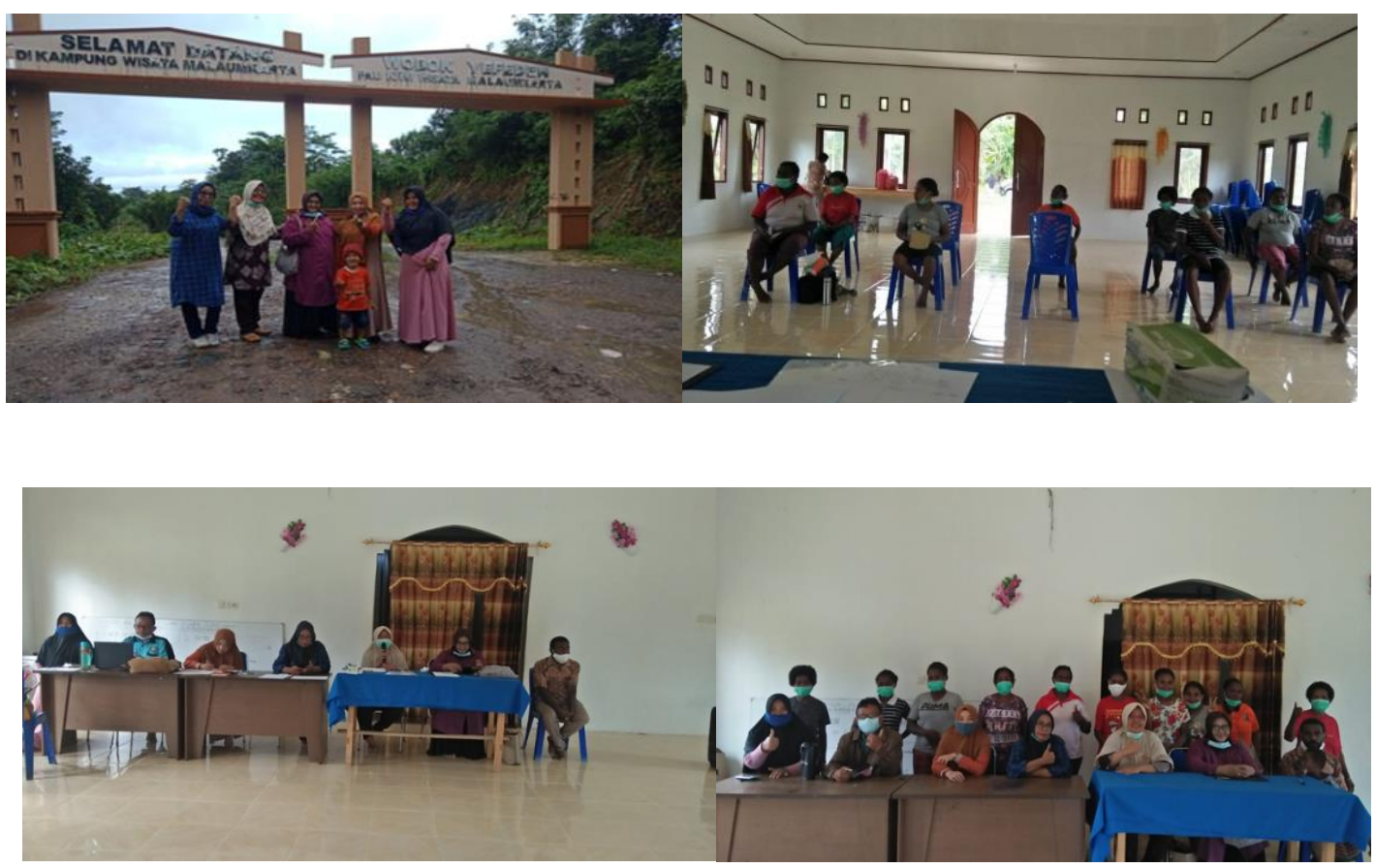

Konsep pemberdayaan bersama laki-laki harus dikedepankan dan menjadi agenda semua negara di dunia ini untuk membentuk cita-cita bersama yaitu masyarakat yang demokratis, adil dan makmur (Baso,Zora Andi,2000).

Perempuan sejak dahulu aktif dalam kegiatan ekonomi dan sosial sebagai petani,pedagang, pekerja (di sektor informal) dan sebagai ibu rumah tangga (Ihromi,Tapi Omas,2006). Demikian juga perempuan Mace Mace Papua kampung Malaumkarta, selain sebagai Ibu rumah tangga, mereka juga sebagai petani, nelayan dan pedagang. Namun pola pikir dan ilmu pengetahuannya tentang bertani, berdagang dan sebagai nelayan masih bersifat tradisional.

Kegiatan Pengabdian Kepada Masyarakat ini yaitu upaya mengangkat derajat masyarakat kampung Malaumkarta melalui proses pemberdayaan Mace Mace Papua sebagai Sumber Daya Manusia agar dapat meningkatkan poduktivitas usaha mereka, sehingga. Diharapkan dapat menambah penghasilan rumah tangga yang berpengaruh pada peningkatan kesejahteraan keluarga masyarakat kampung Malumkarta sebagai Daerah Tujuan Wisata Pantai di Distrik Makbon Kabupaten Sorong.

Kegiatan Pengabdian Kepada Masyarakat yang Kami lakukan di Kampung Malaumkarta Distrik Makbon adalah program kerja dengan menggunakan pendekatan dan penyuluhan bersama dengan pemerintahan setempat dan Mace Mace Papua. Berdasarkan hasil penyuluhan tersebut Kami dapat mengindentifikasi masalah-masalah tentang perempuan yang ada di Kampung Malaumkarta khususnya dalam pemberdayaan perempuan Mace Mace Papua dalam rangka mengembangkan potensi dirinya untuk berkreativitas sehingga diharapkan dapat menghasilkan tambahan penghasilan untuk meningkatkan kesejahteraan keluarga. Masalahmasalah tersebut Kami dapat uraikan sebagai berikut:

1. Masih terbatasnya ilmu pengetahuan dan keterampilan dalam pengolahan sumber daya alam sebagai sumber pendapatan tambahan keluarga. 
2. Kurang mampu dalam segi modal usaha untuk mengembangkan usaha rumah-rumah pondok di areal wisata pantai.

\section{SIMPULAN}

Berdasarkan hasil kegiatan PKM yang Kami laksanakan pada masyarakat Kampung Malaumkarta Distrik Makbon, Kabupaten Sorong bahwa:

Pada dasarnya perempuan Mace Mace Papua kampung Malumkarta sudah mempunyai kesadaran mengembangkan potensi dirinya diluar kegiatannya diranah Domestik (rumah tangga)ke sektor Publik, ini terbukti antara lain dari pondok pondok kecil sebagai tempat berjualan di areal wisata pantai untuk mendapatakan tambahan pendapatan keluarga. Tetapi pola pikir dalam pengelolaan barang dagangan yang dijual masih tradisional, karena keterbatasan wawasan dan ilmu pengetahuan mereka dalam mengolah hasil bumi

\section{SARAN} berikut:

Berdasarkan hasil kegiatan PKM di lapangan, Kami memberikan beberapa saran sebagai

1. Disarankan Pemerintah Kabupaten Sorong melalui dinas terkait yaitu Dinas Pemberdayaan Perempuan Kabupaten Sorong memberikan pelatihan keterampilan dan pembinaan kepada Mace Mace Papua kampung Malumkarta Distrik Makbon secara berkala, sehingga bisa memaksimalkan potensi Mace Mace Papua di kampung Malaumkarta

2. Disarankan Pemerintah Kabupaten Sorong memberikan dukungan modal untuk pengembangan usaha Mace Mace Papua di kampung Malumkarta, yaitu dengan memberikan bantuan modal. Sehingga bisa menunjang proses kegiatan jual beli disekitar daerah tujuan wisata pantai.

3. Diharapkan dengan kegiatan PKM ini, dapat menberikan semangat kepada Mace Mace di kampung Malumkarta Distrik Makbon Kabupaten Sorong untuk mengembangkan potensi diri dalam peningkatan kesejahteraan keluarga.

\section{UCAPAN TERIMA KASIH}

Kami menyadari bahwa terlaksananya kegiatan Pengabdian Kepada Masyarakat ini dapat terlaksana atas kontribusi berbagai pihak, untuk itu Kami mengucapkan terima kasih yang sebesar-besarnya kepada:

1 Ketua Lembaga Penelitian,Publikasi Dan Pengabdian Kepada Masyarakat Universitas Muhammadiyah Sorong berserta jajarannya.

2 Bapak kepala Kampung Malaumkarta beserta jajarannya.

3 Pemerintah Kabupaten Sorong.

4 Seluruh warga Kampung Malaumkarta.

5 Teman-teman Dosen UM-Sorong dalam Tim PKM Kampung Malaumkarta.

\section{DAFTAR PUSTAKA}

Andi Baso, Zohra. 2000. Langkah Perempuan Menuju Tegaknya Hak-Hak Konsumen.YLK:Sulawesi Selatan

Ihromi,Tapi Omas dkk. 2006. Penghapusan Diskriminasi Terhadap Wanita.ALUMNI:Bandung

Laporan Kelompok Kegiatan K2N Mahasiswa UNiversitas Muhammadiyah Sorong. 2020. LP3M: Sorong Lokasi Kampung Malaumkarta Distrik Makbon Kabupaten Sorong Papua Barat 